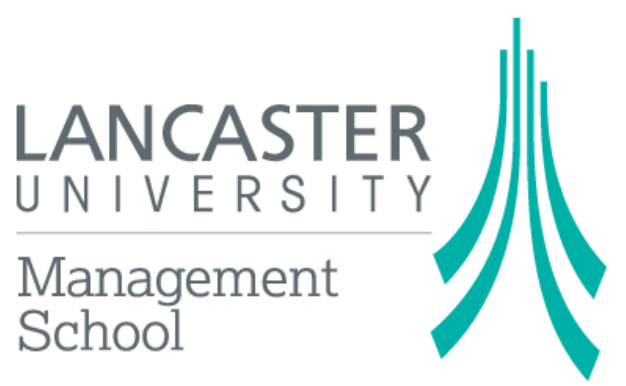

Economics Working Paper Series

2014/002

\title{
The gains from trade in intermediate goods: A Ricardo-Sraffa-Samuelson model
}

\author{
Kwok Tong Soo \\ The Department of Economics \\ Lancaster University Management School \\ Lancaster LA1 4YX \\ UK
}

(C) Authors

All rights reserved. Short sections of text, not to exceed two paragraphs, may be quoted without explicit permission, provided that full acknowledgement is given. 


\title{
The gains from trade in intermediate goods: A Ricardo-Sraffa-Samuelson model ${ }^{*}$
}

\author{
Kwok Tong Soo ${ }^{\dagger}$ \\ Lancaster University
}

August 2014

\begin{abstract}
This paper develops a model of intermediate and final goods trade based on comparative advantage. Firms endogenously decide whether to produce a final good directly using labour, or indirectly using both labour and intermediate inputs. It is shown that the gains from trade in intermediate and final goods exceeds that from trade in final goods alone. Allowing for decreasing trade and coordination costs results in an endogenous change in the structure of production towards a more fragmented structure, with corresponding implications for trade patterns.
\end{abstract}

JEL Classification: F11.

Keywords: Intermediates trade; Comparative advantage; Structure of production.

\footnotetext{
* Thanks to seminar participants at Lancaster University for helpful suggestions. The author is responsible for any errors and omissions.

${ }^{\dagger}$ Department of Economics, Lancaster University Management School, Lancaster LA1 4YX, United Kingdom. Tel: +44(0)1524 594418. Email: k.soo@lancaster.ac.uk
} 


\section{Introduction}

That a large proportion of international trade is trade in intermediate goods has been known since the seminal work of Grubel and Lloyd (1975). Such trade may be viewed as the next step in economic globalisation: if the production process can be broken into several stages, then each stage may be produced in the country that has a comparative advantage in producing that stage. Therefore, trade in intermediate goods should lead to additional gains above those associated with trade in final goods alone.

The original motivation for this paper is a paper by Paul Samuelson (2001) in the Journal of Economic Literature, where he developed a Ricardian (1817) model of international trade in which each of two final goods can also be used as intermediate inputs in the production of the other final good. International trade results in a much larger gain than would otherwise be obtained if goods could not be used as intermediate inputs. Samuelson attributed the insight of using final goods as intermediate goods to Sraffa (1960); Samuelson's (2001) contribution was to introduce the international dimension to Sraffa's idea. Since Samuelson's contribution, Shiozawa $(2007,2009)$ has extended the Ricardo-Sraffa model to many goods and many countries, while Fujimoto and Shiozawa (2011a, b) consider how the model can be used to analyse both inter- and intra-industry competition and trade.

In this paper we extend and generalise the model developed by Samuelson (2001). Whilst Samuelson specified that the intermediate inputs are the same as final goods, we decouple intermediates from final goods. This enables us to consider more possible configurations of production than Samuelson's two (trade in final goods only, and trade in both intermediate and final goods). Here, we consider both domestic and international outsourcing of production; for instance, Fort (2013) shows for a sample of US manufacturers that domestic outsourcing is much more prevalent than international outsourcing. Further, we introduce trade costs and the cost of coordinating intermediates into the model, and show how changing these costs can change not only the quantity of goods produced and traded, but also change the configuration of production in the global economy.

Changes in the structure of production are a key feature of the modern economy. Consider for instance the automobile industry. With Henry Ford's introduction of the moving assembly 
line in 1913, the time it took to build a car was reduced from over 12 hours to less than six hours (Gross, 1997). A key feature of the Ford assembly line was the integration of the entire production process. Gross (1997) notes:

“...[In 1921] Ford was free to embark on a great new project: the design and construction of the world's largest and most efficient automobile factory at River Rouge, near Detroit. Arrayed over 2,000 acres, it would include 90 miles of railroad track and enough space for 75,000 employees to produce finished cars from raw material in the span of just forty-one hours. River Rouge had its own power plant, iron forges, and fabricating facilities.” (Gross, 1997, p. 85).

Contrast this to the $3^{\text {rd }}$ generation Apple iPod (released in 2003), for which the hard drive was manufactured in China (as was the final assembly), the display in Japan, the video processor in Taiwan or Singapore, the CPU in the US or Taiwan, and the memory in Korea (Linden et al, 2007). Sturgeon (2002) documents this trend in modular production networks, while Brown and Linden (2005) discuss offshoring in the semiconductor industry. Offshoring has been the topic of a US Government Accountability Office Report to Congressional Committees (US Government Accountability Office, 2006).

International trade in intermediate goods and the international fragmentation of production have been subjects of a large amount of research. An early formulation was provided in a monopolistic competition model by Ethier (1982). More directly related to the international fragmentation of production are Jones and Sanyal (1982), Jones and Kierzkowski (1990), and the literature summarised by Jones's Ohlin lectures (Jones, 2000). Of this early work, the present paper is most closely related to Sanyal (1983), in which the production of both the two final goods is divided into two stages. In Sanyal (1983), production of each final good must occur via production of intermediates, whereas in Samuelson (2001) and the present paper, firms endogenously choose whether to produce the final good by means of intermediate goods or by means of direct production.

More recent literature on the international fragmentation of production includes Yi (2003), who develops a perfectly competitive model of vertical specialisation. Feenstra and Hanson (1996, 1997) develop a model of offshoring based on the many-good Heckscher-Ohlin model, while Grossman and Rossi-Hansberg (2008) develop a model of international trade in 
tasks, and Rodriguez-Clare's (2010) model extends the Eaton and Kortum (2002) model to allow for offshoring. Compared to this work, the present paper does not assume that the production process must be divided into many steps, instead allowing it to be a choice made by firms. In this sense the paper is similar to Antras (2003), who analyses the situations in which firms will choose to engage in arms-length international outsourcing as opposed to producing abroad as a multinational firm. Unlike Antras (2003), where contract incompleteness and intra-firm trade take centre stage, in the present paper the equilibrium structure of production is determined solely by cost considerations, and all transactions are assumed to take place between rather than within firms. The existing literature has been ably summarised in Feenstra’s Ohlin lectures (Feenstra, 2009).

A key result of the model developed in this paper is that both domestic and foreign outsourcing lead to productivity gains. This is distinct from some of the literature such as Antras and Helpman (2004) and Helpman et al (2004), in which firms have innate differences in their productivity, and these differences are what drives the structure of production (although see Grossman and Helpman (2002) for a model of offshoring without heterogeneity across firms). The empirical evidence has shown strong support for the idea that both domestic and foreign outsourcing have positive effects on productivity, controlling for the endogeneity of outsourcing. Recent work in this area includes Amiti and Wei (2006), Gorg et al (2008), Knittel and Stango (2012) and Fort (2013). Olsen (2006) offers a review of the literature, while Houseman (2007) warns of measurement problems in productivity in the presence of outsourcing and offshoring.

The next section develops the model and the possible outcomes under autarky. Section 3 shows what happens when international trade is allowed. Section 4 provides some concluding comments.

\section{The model: Autarky}

Because our primary interest is in the implications of the different structures of production that emerge in the model, throughout the paper we shall focus on situations where both sectors adopt the same production structure; situations in which each sector adopts different production structures may be analysed by comparison with the situations discussed below. 


\subsection{Direct production}

First consider the model with no international trade, for the case where there are no intermediate goods. There are two final goods, $X_{1}$ and $X_{2}$. Utility takes the following CobbDouglas form:

$$
U=C_{X_{1}}^{\alpha} C_{X_{2}}^{1-\alpha} \quad 0<\alpha<1
$$

All markets are perfectly competitive. Labour is the only factor of production, and is inelastically supplied. The labour endowment is $\bar{L}$. The production functions exhibit constant returns to scale and take the following form:

$$
Q_{X_{1}}=A_{X_{1}} L_{X_{1}} \quad Q_{X_{2}}=A_{X_{2}} L_{X_{2}}
$$

Where $A_{X_{1}}$ and $A_{X_{2}}$ are the productivity parameters. Call these the direct production functions, since they employ labour to produce final goods directly. From the consumer's first order conditions and the firm's zero profit conditions we have:

$$
\frac{p_{X_{1}}}{p_{X_{2}}}=\frac{A_{X_{2}}}{A_{X_{1}}}=\frac{\alpha}{1-\alpha}\left(\frac{C_{X_{2}}}{C_{X_{1}}}\right)
$$

From equation (3) and the goods and labour market clearing conditions, the labour used in each good is given by:

$$
L_{X_{1}}=\alpha \bar{L} \quad L_{X_{2}}=(1-\alpha) \bar{L}
$$

Hence, output of each good is:

$$
Q_{X_{1}}=A_{X_{1}} \alpha \bar{L} \quad Q_{X_{2}}=A_{X_{2}}(1-\alpha) \bar{L}
$$

So national utility under direct production is:

$$
U_{D}=\left[A_{X_{1}} \alpha\right]^{\alpha}\left[A_{X_{2}}(1-\alpha)\right]^{1-\alpha} \bar{L}
$$

This provides us with a benchmark with which to compare the results for different organisational forms below.

\subsection{Indirect production}

Now suppose that in addition to the production functions above, there is another way of producing the two final goods $X_{1}$ and $X_{2}$ involving the use of intermediate inputs $Y_{1}$ and $Y_{2}$. Let $Y_{1}$ be used only in the production of $X_{1}$, and $Y_{2}$ be used only in the production of $X_{2}$. Suppose these indirect production functions take the following fixed-proportions form:

$$
Q_{X_{1}}=\min \left\{A_{X_{01}} L_{X_{01}}, A_{X_{11}} Q_{Y_{1}}\right\}
$$




$$
Q_{X_{2}}=\min \left\{A_{X_{02}} L_{X_{02}}, A_{X_{22}} Q_{Y_{2}}\right\}
$$

Where, as before, the $A$ terms represent productivity parameters. That is, under indirect production, production of $X_{1}$ requires the use of both labour and $Y_{1}$, and production of $X_{2}$ requires both labour and $Y_{2}$. This is the main point of departure between our model and that of Samuelson (2001), where $X_{1}$ is used in the production of $X_{2}$, and vice versa. Following Samuelson (2001), suppose that indirect production occurs in both final goods sectors. Let the production functions of the intermediate inputs take the following form:

$$
Q_{Y_{1}}=A_{Y_{1}} L_{Y_{1}} \quad Q_{Y_{2}}=A_{Y_{2}} L_{Y_{2}}
$$

The cost functions for the final goods $X_{1}$ and $X_{2}$ under indirect production are:

$$
p_{X_{1}}=\frac{w}{A_{X_{01}}}+\frac{p_{Y_{1}}}{A_{X_{11}}} \quad p_{X_{2}}=\frac{w}{A_{X_{02}}}+\frac{p_{Y_{2}}}{A_{X_{22}}}
$$

Since the cost functions of the intermediate goods $Y_{1}$ and $Y_{2}$ are

$$
p_{Y_{1}}=\frac{w}{A_{Y_{1}}} \quad p_{Y_{2}}=\frac{w}{A_{Y_{2}}}
$$

Substituting (10) into the cost functions for the final goods (9) and solving gives:

$$
\frac{p_{X_{1}}}{p_{X_{2}}}=\left[\frac{A_{X_{02}} A_{Y_{2}} A_{X_{22}}}{A_{X_{01}} A_{Y_{1}} A_{X_{11}}}\right]\left[\frac{A_{Y_{1}} A_{X_{11}}+A_{X_{01}}}{A_{Y_{2}} A_{X_{22}}+A_{X_{02}}}\right]=\frac{\alpha}{1-\alpha}\left(\frac{C_{X_{2}}}{C_{X_{1}}}\right)
$$

Since consumption equals output in autarky, substituting from the production functions (7a), (7b) and (8) above gives the ratio of the consumption of the two final goods:

$$
\frac{C_{X_{2}}}{C_{X_{1}}}=\frac{A_{X_{02}} L_{X_{02}}}{A_{X_{01}} L_{X_{01}}}=\frac{A_{X_{22}} A_{Y_{2}} L_{Y_{2}}}{A_{X_{11}} A_{Y_{1}} L_{Y_{1}}}
$$

Substituting this into the price ratio (11) and solving for relative labour use in each sector gives:

$$
\begin{aligned}
& \frac{L_{X_{02}}}{L_{X_{01}}}=\left(\frac{1-\alpha}{\alpha}\right)\left(\frac{A_{Y_{2}} A_{X_{22}}}{A_{Y_{1}} A_{X_{11}}}\right)\left(\frac{A_{Y_{1}} A_{X_{11}}+A_{X_{01}}}{A_{Y_{2}} A_{X_{22}}+A_{X_{02}}}\right) \\
& \frac{L_{Y_{2}}}{L_{Y_{1}}}=\left(\frac{1-\alpha}{\alpha}\right)\left(\frac{A_{X_{02}}}{A_{X_{01}}}\right)\left(\frac{A_{Y_{1}} A_{X_{11}}+A_{X_{01}}}{A_{Y_{2}} A_{X_{22}}+A_{X_{02}}}\right)
\end{aligned}
$$

In addition, from the production functions (7a) and (7b), since labour and intermediate inputs are used in fixed proportions, we have:

$$
\begin{array}{llll}
A_{X_{01}} L_{X_{01}}=A_{X_{11}} A_{Y_{1}} L_{Y_{1}} & \leftrightarrow & & L_{X_{01}}=\frac{A_{X_{11}} A_{Y_{1}}}{A_{X_{01}}} L_{Y_{1}} \\
A_{X_{02}} L_{X_{02}}=A_{X_{22}} A_{Y_{2}} L_{Y_{2}} & \leftrightarrow & L_{X_{02}}=\frac{A_{X_{22}} A_{Y_{2}}}{A_{X_{02}}} L_{Y_{2}}
\end{array}
$$

Full employment implies that $L_{X_{01}}+L_{X_{02}}+L_{Y_{1}}+L_{Y_{2}}=\bar{L}$. Substituting from (13a), (13b), (14a) and (14b) into this expression and simplifying gives the following expressions for the labour used in each of the four sectors: 


$$
\begin{aligned}
L_{Y_{1}} & =\frac{\alpha A_{X_{01}} \bar{L}}{A_{Y_{1}} A_{X_{11}}+A_{X_{01}}} & L_{Y_{2}} & =\frac{(1-\alpha) A_{X_{02}} \bar{L}}{A_{Y_{2}} A_{X_{22}}+A_{X_{02}}} \\
L_{X_{01}} & =\frac{\alpha A_{Y_{1}} A_{X_{11}} \bar{L}}{A_{Y_{1}} A_{X_{11}}+A_{X_{01}}} & L_{X_{02}} & =\frac{(1-\alpha) A_{Y_{2}} A_{X_{22}} \bar{L}}{A_{Y_{2}} A_{X_{22}}+A_{X_{02}}}
\end{aligned}
$$

Note that $L_{Y_{1}}+L_{X_{01}}=\alpha \bar{L}$ and $L_{Y_{2}}+L_{X_{02}}=(1-\alpha) \bar{L}$; total labour employed in each sector is the same as under direct production, and does not depend on the technology parameters. Substituting (15a) and (15b) into the production functions (7a), (7b) and (8) and the utility function (1) enables us to solve for national utility under indirect production:

$$
U_{I}=\left[\frac{\alpha A_{Y_{1}} A_{X_{11}} A_{X_{01}}}{A_{Y_{1}} A_{X_{11}}+A_{X_{01}}}\right]^{\alpha}\left[\frac{(1-\alpha) A_{Y_{2}} A_{X_{22}} A_{X_{02}}}{A_{Y_{2}} A_{X_{22}}+A_{X_{02}}}\right]^{1-\alpha} \bar{L}
$$

There are gains from indirect production provided $U_{I}>U_{D}$. This will be the case if the technology parameters associated with indirect production are sufficiently large relative to the technology parameters associated with direct production. That is, firms will endogenously choose indirect production instead of direct production if there are productivity gains from indirect production. Note that it is possible for there to be direct production in one sector but not in the other sector; this again depends on the technology parameters.

\subsection{Coordination costs}

Now suppose that there are coordination costs involved in engaging in indirect production. These may be the costs of contracting with input suppliers, or the transport cost of shipping the intermediate good to the final good producer, or the cost of coordinating specifications of inputs. There are no coordination costs involved with direct production. Suppose that the coordination cost is the same across goods. Let $\beta<1$ be the fraction of a final good that is available for consumption after incurring the coordination cost involved in indirect production; $1-\beta$ is therefore the coordination cost, with lower values of $\beta$ indicating higher coordination cost. Hence coordination costs are analogous to iceberg-type trade costs, and parallel the use of these costs in Grossman and Rossi-Hansberg (2008). The indirect production functions will become:

$$
\begin{aligned}
& Q_{X_{1}}=\min \left\{\beta A_{X_{01}} L_{X_{01}}, \beta A_{X_{11}} Q_{Y_{1}}\right\} \\
& Q_{X_{2}}=\min \left\{\beta A_{X_{02}} L_{X_{02}}, \beta A_{X_{22}} Q_{Y_{2}}\right\}
\end{aligned}
$$


Because the coordination cost is assumed to be identical across goods, it has no impact on relative prices and consumption if both sectors engage in indirect production ${ }^{3}$ :

$$
\begin{aligned}
& \frac{p_{X_{1}}}{p_{X_{2}}}=\left[\frac{A_{X_{02}} A_{Y_{2}} A_{X_{22}}}{A_{X_{01}} A_{Y_{1}} A_{X_{11}}}\right]\left[\frac{A_{Y_{1}} A_{X_{11}}+A_{X_{01}}}{A_{Y_{2}} A_{X_{22}}+A_{X_{02}}}\right] \\
& \frac{C_{X_{2}}}{C_{X_{1}}}=\frac{A_{X_{02}} L_{X_{02}}}{A_{X_{01}} L_{X_{01}}}=\frac{A_{X_{22}} A_{Y_{2}} L_{Y_{2}}}{A_{X_{11}} A_{Y_{1}} L_{Y_{1}}}
\end{aligned}
$$

Hence there is also no impact on the labour used in each sector; the expressions in equations (15a) and (15b) continue to hold. Output of $X_{1}$ and $X_{2}$ through indirect production are given by:

$$
Q_{X_{1}}=\frac{\alpha \beta A_{X_{01}} A_{Y_{1}} A_{X_{11}} \bar{L}}{A_{Y_{1}} A_{X_{11}}+A_{X_{01}}} \quad Q_{X_{2}}=\frac{(1-\alpha) \beta A_{X_{02}} A_{Y_{2}} A_{X_{22}} \bar{L}}{A_{Y_{2}} A_{X_{22}}+A_{X_{02}}}
$$

As before, indirect production will be used if output via this means exceeds that through direct production. Equation (20) shows that the coordination cost acts as a productivity cost to the firm. Thus it can be seen that high coordination costs will reduce the likelihood that indirect production will be chosen instead of direct production. That is, firms will trade off possible productivity gains from indirect production against the productivity loss from the coordination cost. Comparing the outputs in equation (20) with those in equation (5) allows us to solve for the threshold value of $\beta$ above which firms will decide to engage in indirect as opposed to direct production:

$$
\widehat{\beta_{1}}=\frac{A_{X_{1}}\left(A_{Y_{1}} A_{X_{11}}+A_{X_{01}}\right)}{A_{X_{01}} A_{Y_{1}} A_{X_{11}}} \quad \widehat{\beta_{2}}=\frac{A_{X_{2}}\left(A_{Y_{2}} A_{X_{22}}+A_{X_{02}}\right)}{A_{X_{02}} A_{Y_{2}} A_{X_{22}}}
$$

\section{The international organisation of production}

In this section we extend the model above to allow for international trade. Trade is always assumed to be balanced. In the first two subsections below, we assume no trade or coordination costs; these are introduced in the following sections. Suppose there are two countries, Home and Foreign, with Foreign variables denoted with an asterisk. Consumer preferences are identical in the two countries. In the previous section we have been flexible with regards to the precise magnitudes of various parameters. In this section, to make progress (and to prevent the paper from degenerating into a taxonomy of possible cases), we make the following assumptions with regard to the parameter values of the model ${ }^{4}$, and in all

\footnotetext{
${ }^{3}$ The coordination cost will of course affect relative prices if one sector engages in direct production (and hence avoids the coordination cost), while the other sector engages in indirect production.

${ }^{4}$ These values are different from those in Samuelson (2001), and have been chosen to illustrate the key features of the model. Appendix D shows the outcome of the model using Samuelson's parameter values.
} 
cases focus on equilibria in which firms in both sectors choose the same structure of production, whether direct or indirect:

$$
\begin{array}{llll}
A_{X_{1}}=4 & A_{X_{2}}=2 & A_{Y_{1}}=4 & A_{Y_{2}}=8 \\
A_{X_{01}}=A_{X_{11}}=8 & & A_{X_{02}}=A_{X_{22}}=4 & \\
A_{X_{1}}^{*}=2 & A_{X_{2}}^{*}=4 & A_{Y_{1}}^{*}=8 & A_{Y_{2}}^{*}=4 \\
A_{X_{01}}^{*}=A_{X_{11}}^{*}=4 & & A_{X_{02}}^{*}=A_{X_{22}}^{*}=8 & \\
\alpha=0.5 & & \bar{L}=\overline{L^{*}}=2
\end{array}
$$

Hence the two countries are symmetric in terms of their technology. In terms of direct production, Home has a comparative advantage in the production of $X_{1}$. On the other hand, in terms of indirect production, Foreign has a comparative advantage in the production of $Y_{1}$, which is used in the production of $X_{1}$. However, Home still has a comparative advantage in assembling $X_{1}$ from $Y_{1}$. Both countries are assumed to be the same size, and the two goods are symmetric from the consumer's viewpoint ${ }^{5}$.

As a basis for comparison with the results below, note that, given the parameter values above, if there are no coordination or trade costs, then in autarky, under direct production, each country's utility is 2.83 . Under indirect production, each country's utility is 4.77 , an increase of 69 percent over utility under direct production. Hence given the parameter values, there is a productivity gain from indirect production. Also, the threshold values for $\widehat{\beta_{1}}$ and $\widehat{\beta_{2}}$ are 0.63 and 0.56 for Home, and vice versa for Foreign. That is, if $\beta_{1}$ and $\beta_{2}$ are lower than these values, the productivity cost of coordinating inputs from suppliers outweighs the productivity benefits of indirect production, and both countries would produce both goods using direct rather than indirect means.

\subsection{No trade and coordination costs: International trade in final goods only}

There are two sub-cases here. First, parameter values may be such that indirect production will occur in both countries. Second, parameter values may be such that direct production will occur in both countries.

\footnotetext{
${ }^{5}$ The symmetry of the model makes it much easier to solve, although where possible, to obtain more general results we will not rely on symmetry.
} 
Consider first the case of indirect production. In this case, since Home has a comparative advantage in the production of $X_{1}$, Home will specialise in the production of $X_{1}$ and will export $X_{1}$ in exchange for imports of $X_{2}$ from Foreign. The equilibrium conditions are shown in Appendix A, and are obtained following the same steps as in Section 2 above. Substituting the expressions for relative labour demands (A4), (A5), (A6) and (A7) into the labour market clearing condition (A8) for the two countries and solving for labour in each sector, we have:

$$
\begin{aligned}
L_{Y_{1}} & =\frac{A_{X_{01}} \bar{L}}{A_{Y_{1}} A_{X_{11}}+A_{X_{01}}} & L_{X_{01}} & =\frac{A_{Y_{1}} A_{X_{11}} \bar{L}}{A_{Y_{1}} A_{X_{11}}+A_{X_{01}}} \\
L_{Y_{2}}^{*} & =\frac{A_{X_{02}}^{*} \overline{L^{*}}}{A_{Y_{2}}^{*} A_{X_{22}}^{*}+A_{X_{02}}^{*}} & L_{X_{02}}^{*} & =\frac{A_{Y_{2}}^{*} A_{X_{22}}^{*} \bar{L}^{*}}{A_{Y_{2}}^{*} A_{X_{22}}^{*}+A_{X_{02}}^{*}}
\end{aligned}
$$

Because each country is specialised in its comparative advantage final good, its share of world income is equal to the share of this good in consumer expenditure. Hence, substituting from the labour allocation equations (23a) and (23b) into the production functions (7a) and (7b) and then into the utility function (1), the expression for utility in the two countries is:

$$
\begin{aligned}
& U_{H}=\alpha\left[\frac{A_{Y_{1}} A_{X_{11}} A_{X_{01}} \bar{L}}{A_{Y_{1}} A_{X_{11}}+A_{X_{01}}}\right]^{\alpha}\left[\frac{A_{Y_{2}}^{*} A_{X_{22}}^{*} A_{X_{02}}^{*} \bar{L}^{*}}{A_{Y_{2}}^{*} A_{X_{22}}^{*}+A_{X_{02}}^{*}}\right]^{1-\alpha} \\
& U_{F}=(1-\alpha)\left[\frac{A_{Y_{1}} A_{X_{11}} A_{X_{01}} \bar{L}}{A_{Y_{1}} A_{X_{11}}+A_{X_{01}}}\right]^{\alpha}\left[\frac{A_{Y_{2}}^{*} A_{X_{22}}^{*} A_{X_{02}}^{*} \bar{L}^{*}}{A_{Y_{2}}^{*} A_{X_{22}}^{*}+A_{X_{02}}^{*}}\right]^{1-\alpha}
\end{aligned}
$$

Assuming no trade or coordination costs, substituting the parameter values into this expression and solving yields utility of 6.4 in both countries. This is higher than under autarky with indirect production, so there are gains from trade in final goods.

The other case is when parameter values are such that direct production occurs in each country, and then each final good is exported to the other country. In that case, all Home labour $\bar{L}$ is used in producing $X_{1}$, while all Foreign labour $\overline{L^{*}}$ is used in producing $X_{2}$, so in the absence of trade costs, since specialising in $X_{1}$ gives Home a share $\alpha$ of world income, we have:

$$
U_{H}=\alpha\left[A_{X_{1}} \bar{L}\right]^{\alpha}\left[A_{X_{2}}^{*} \bar{L}^{*}\right]^{1-\alpha} \quad U_{F}=(1-\alpha)\left[A_{X_{1}} \bar{L}\right]^{\alpha}\left[A_{X_{2}}^{*} \bar{L}^{*}\right]^{1-\alpha}
$$

Given the parameter values assumed above, utility in both countries is equal to 4.0. What this tells us is that there are productivity gains from specialisation and trade, but that given the parameter values, the gain from indirect domestic production under autarky is larger than the gain from direct production combined with international trade. Clearly the combination of domestic indirect production and international trade in final goods yields the greatest gain. 


\subsection{No trade and coordination costs: International trade in both intermediate and final goods}

If international trade is allowed in both intermediate and final goods, then Home will specialise in production of $Y_{2}$, which it will export to Foreign in exchange for $Y_{1}$, which Home will then use in production of $X_{1}$, exporting it to Foreign in exchange for $X_{2}$. Since the two countries are symmetric in every way, wages are equalised in the two countries. The equilibrium conditions are shown in Appendix B. As before, substituting from the labour demand conditions (B5), (B6), (B7) and (B8) into the labour market clearing conditions for the two countries (B9) and simplifying gives the following expressions for the labour used in each of the four sectors:

$$
\begin{array}{ll}
L_{X_{01}}=[B]^{-1} \bar{L} & L_{Y_{2}}=\left(1-[B]^{-1}\right) \bar{L} \\
L_{X_{02}}^{*}=[D]^{-1} \overline{L^{*}} & L_{Y_{1}}^{*}=\left(1-[D]^{-1}\right) \overline{L^{*}}
\end{array}
$$

where

$$
\begin{aligned}
& {[B]=1+\left(\frac{1-\alpha}{\alpha}\right)\left(\frac{A_{X_{02}}^{*}}{A_{X_{11}} A_{Y_{1}}^{*}}\right)\left(\frac{A_{X_{11}} A_{Y_{1}}^{*}+A_{X_{01}}}{A_{X_{22}}^{*} A_{Y_{2}}+A_{X_{02}}^{*}}\right)} \\
& {[D]=1+\left(\frac{\alpha}{1-\alpha}\right)\left(\frac{A_{X_{01}}}{A_{X_{22}}^{*} A_{Y_{2}}}\right)\left(\frac{A_{X_{22}}^{*} A_{Y_{2}}+A_{X_{02}}^{*}}{A_{X_{11}} A_{Y_{1}}^{*}+A_{X_{01}}}\right)}
\end{aligned}
$$

Substituting (26a) and (26b) into the production functions (7a), (7b) and (8) yields the output of each of the two final goods $X_{1}$ and $X_{2}$. Consumption of each final good in each country depends on national income; however, national income (defined as the value of final good output) now depends on the value of both countries' final good, since each country also produces the intermediate good which is used in the other country. The symmetry of the model allows us to normalise wages in both countries to 1. From equation (B1) in Appendix $\mathrm{B}$, the price of $X_{1}$ is:

$$
p_{X_{1}}=\frac{A_{X_{11}} A_{Y_{1}}^{*}+A_{X_{01}}}{A_{X_{01}} A_{X_{11}} A_{Y_{1}}^{*}}
$$

Hence, substituting from the production function (7a) and the labour demand (26a), the value of Home's output of $X_{1}$ is:

$$
p_{X_{1}} Q_{X_{1}}=\frac{A_{X_{11}} A_{Y_{1}}^{*}+A_{X_{01}}}{A_{X_{11}} A_{Y_{1}}^{*}[B]} \bar{L}
$$

Home's GDP may be defined as the total value of output minus the value of intermediate goods used:

$$
G D P_{H}=p_{X_{1}} Q_{X_{1}}-p_{Y_{1}}^{*} Q_{Y_{1}}^{*}+p_{Y_{2}} Q_{Y_{2}}
$$




$$
\begin{aligned}
& =p_{X_{1}} Q_{X_{1}}-L_{Y_{1}}^{*}+L_{Y_{2}} \\
& =p_{X_{1}} Q_{X_{1}}
\end{aligned}
$$

Where the second equality comes from substituting from the cost functions (10) and the production functions (8) for $Y_{1}$ and $Y_{2}$ into the above expression, and the third equality comes from the assumption of symmetry between the two countries. Foreign's GDP is, analogously:

$$
G D P_{F}=p_{X_{2}}^{*} Q_{X_{2}}^{*}=\frac{A_{X_{22}}^{*} A_{Y_{2}}+A_{X_{02}}^{*}}{A_{X_{22}}^{*} A_{Y_{2}}[D]} \bar{L}^{*}
$$

Home's share of world income is therefore:

$$
S_{H}=\frac{G D P_{H}}{G D P_{H}+G D P_{F}}=\frac{\frac{A_{X_{11}} A_{Y_{1}}^{*}+A_{X_{01}}}{A_{X_{11}} A_{Y_{1}}^{*}[B]}}{\left[\frac{{ }_{X_{11}} A_{Y_{1}}^{*}+A_{X_{01}}}{A_{X_{11}} A_{Y_{1}}^{*}[B]}\right]+\left[\frac{A_{X_{22}}^{*} A_{Y_{2}}+A_{X_{02}}^{*}}{A_{X_{22}}^{*} A_{Y_{2}}[D]} \bar{L}^{*}\right]}
$$

Since preferences are homothetic, we can then make use of this to obtain the equilibrium consumption levels in each country:

$$
\begin{array}{ll}
C_{X_{1}}=S_{H} A_{X_{01}}[B]^{-1} \bar{L} & C_{X_{1}}^{*}=\left(1-S_{H}\right) A_{X_{01}}[B]^{-1} \bar{L} \\
C_{X_{2}}=S_{H} A_{X_{02}}^{*}[D]^{-1} \overline{L^{*}} & C_{X_{2}}^{*}=\left(1-S_{H}\right) A_{X_{02}}^{*}[D]^{-1} \overline{L^{*}}
\end{array}
$$

Substituting these consumption levels into the utility function (1) yields utility equal to 7.11 in both countries. These values are higher than when only trade in final goods is allowed. Therefore, there are additional productivity gains from trading in intermediate as well as final goods, as it enables countries to specialise in the intermediate and final goods in which they have a comparative advantage. This is what Samuelson (2001) refers to as the "Sraffian bonus": a gain from international trade which goes beyond the gains from the Ricardian model.

\subsection{Trade and coordination costs: Trade in final goods only}

So far the welfare calculations have been performed assuming no coordination or trade costs. In this section and the next, we introduce these costs. Coordination costs have been defined in Section 2.3 above. For trade costs, suppose that international trade occurs with an iceberg trade cost so that for every unit shipped abroad, only $\tau<1$ units arrive; $1-\tau$ is therefore the trade cost. Trade costs are the same for all goods.

Our focus in this section will be on obtaining expressions for the threshold values of trade costs such that if trade costs are lower than the threshold values, international trade occurs, but otherwise there will be no trade. As noted above in Section 2.3, when both sectors engage 
in indirect production, the introduction of coordination costs which are identical across sectors has no impact on the share of labour used in each sector. Similarly, when there is only trade in final goods, trade costs which are identical across sectors can be shown to have no impact on the share of labour used in each sector. Consider first the case when firms in both sectors engage in indirect production. The consumer's maximisation problem yields the same solution as in equation (3), in terms of domestic prices. On the production side, the relative price of $X_{1}$ to $X_{2}$ in the Home country (the analogue of equation (11)) is a function of $\tau$ :

$$
\frac{p_{X_{1}}}{p_{X_{2}}}=\tau\left[\frac{A_{X_{02}}^{*} A_{Y_{2}}^{*} A_{X_{22}}^{*}}{A_{X_{01}} A_{Y_{1}} A_{X_{11}}}\right]\left[\frac{A_{Y_{1}} A_{X_{11}}+A_{X_{01}}}{A_{Y_{2}}^{*} A_{X_{22}}^{*}+A_{X_{02}}^{*}}\right]
$$

On the other hand, the consumption ratio analogous to equation (12) is now:

$$
\frac{C_{X_{2}}}{C_{X_{1}}}=\frac{\tau A_{X_{02}}^{*} L_{X_{02}}^{*}}{A_{X_{01}} L_{X_{01}}}=\frac{\tau A_{X_{22}}^{*} A_{Y_{2}}^{*} L_{Y_{2}}^{*}}{A_{X_{11}} A_{Y_{1}} L_{Y_{1}}}
$$

Hence dividing equation (34) by equation (35), relative expenditure shares on the two final goods are the same as in the case without trade and coordination costs, and the solution to the labour shares remains as in equations (23a) and (23b). The only difference is that consumption of $X_{2}$ in Home and $X_{1}$ in Foreign is reduced by the trade cost, to $\tau$ times the consumption without trade costs. Consumption of $X_{1}$ and $X_{2}$ in the two countries is therefore:

$$
\begin{array}{rlrl}
C_{X_{1}} & =\frac{\alpha \beta A_{Y_{1}} A_{X_{11}} A_{X_{01}} \bar{L}}{A_{Y_{1}} A_{X_{11}}+A_{X_{01}}} & C_{X_{1}}^{*} & =\frac{\tau(1-\alpha) \beta A_{Y_{1}} A_{X_{11}} A_{X_{01}} \bar{L}}{A_{Y_{1}} A_{X_{11}}+A_{X_{01}}} \\
C_{X_{2}}=\frac{\tau \alpha \beta A_{Y_{2}}^{*} A_{X_{22}}^{*} A_{X_{02}}^{*} \bar{L}^{*}}{A_{Y_{2}}^{*} A_{X_{22}}^{*}+A_{X_{02}}^{*}} & C_{X_{2}}^{*}=\frac{(1-\alpha) \beta A_{Y_{2}}^{*} A_{X_{22}}^{*} A_{X_{02}}^{*} \bar{L}^{*}}{A_{Y_{2}}^{*} A_{X_{22}}^{*}+A_{X_{02}}^{*}}
\end{array}
$$

Since trade is assumed to be balanced, comparing the outputs (consumption) in equation (20) under indirect production in autarky to those in equations (36a) and (36b) under international trade in final goods yields the threshold values of $\tau_{X_{1}}$ and $\tau_{X_{2}}$ above which the two countries will benefit from and hence engage in international trade:

$$
\begin{aligned}
& \widehat{\tau_{X_{1}}}=\left(\frac{\alpha}{1-\alpha}\right)\left(\frac{A_{X_{01}}^{*} A_{Y_{1}}^{*} A_{X_{11}}^{*}}{A_{X_{01}} A_{Y_{1}} A_{X_{11}}}\right)\left(\frac{A_{Y_{1}} A_{X_{11}}+A_{X_{01}}}{A_{Y_{1}}^{*} A_{X_{11}}^{*}+A_{X_{01}}^{*}}\right) \frac{\overline{L^{*}}}{\bar{L}} \\
& \widehat{\tau_{X_{2}}}=\left(\frac{1-\alpha}{\alpha}\right)\left(\frac{A_{X_{02}} A_{Y_{2}} A_{X_{22}}}{A_{X_{02}}^{*} A_{Y_{2}}^{*} A_{X_{22}}^{*}}\right)\left(\frac{A_{Y_{2}}^{*} A_{X_{22}}^{*}+A_{X_{02}}^{*}}{A_{Y_{2}} A_{X_{22}}+A_{X_{02}}}\right) \frac{\bar{L}}{\overline{L^{*}}}
\end{aligned}
$$

Given the parameter values defined above, the threshold values of $\widehat{\tau_{X_{1}}}$ and $\widehat{\tau_{X_{2}}}$ are 0.56 .

On the other hand, suppose that coordination costs are sufficiently high so that direct production occurs in both goods. Then once again the trade costs which are identical across sectors have no effect on labour shares, so equilibrium consumption levels are reduced by the trade cost $\tau$ when the good is imported: 


$$
\begin{array}{rlrl}
C_{X_{1}} & =\alpha A_{X_{1}} \bar{L} & C_{X_{1}}^{*} & =(1-\alpha) \tau A_{X_{1}} \bar{L} \\
C_{X_{2}} & =\alpha \tau A_{X_{2}}^{*} \overline{L^{*}} & C_{X_{2}}^{*}=(1-\alpha) A_{X_{2}}^{*} \overline{L^{*}}
\end{array}
$$

Comparing the consumption under international trade with the consumption/output under autarky in equation (5), the threshold values of $\widehat{\tau_{X_{1}}}$ and $\widehat{\tau_{X_{2}}}$ are given by:

$$
\widehat{\tau_{X_{1}}}=\left(\frac{\alpha}{1-\alpha}\right)\left(\frac{A_{X_{1}}^{*}}{A_{X_{1}}}\right) \frac{\overline{L^{*}}}{\bar{L}} \quad \widehat{\tau_{X_{2}}}=\left(\frac{1-\alpha}{\alpha}\right)\left(\frac{A_{X_{2}}}{A_{X_{2}}^{*}}\right) \bar{L}
$$

Substituting from the assumed values of the parameters above yields $\widehat{\tau_{X_{1}}}=\widehat{\tau_{X_{2}}}=0.5$. Given these parameter values, trade costs can be higher under direct production compared with under indirect production, and still allow countries to gain from international trade in final goods; however, this result does not generalise to different parameter values.

\subsection{Trade and coordination costs: Trade in intermediate and final goods}

In this section, we consider the case of international trade in both intermediate and final goods. It may seem reasonable from Antras (2003) to assume that the coordination costs in international trade exceed those in domestic trade. Let the coordination cost be the same across goods. Hence define $\left(1-\beta_{T}\right)>(1-\beta)$ as the coordination costs of indirect production when the inputs are imported. In this section we seek to obtain the threshold values of $\beta_{T}$ such that for values greater than the threshold value, trade in both intermediate and final goods will occur, but if not, only trade in final goods (with domestic indirect production) will occur as in Section 3.3 above.

Since Home specialises in $X_{1}$ and $Y_{2}$, and Foreign in $X_{2}$ and $Y_{1}$, the production functions are now:

$$
\begin{aligned}
Q_{X_{1}} & =\min \left\{\beta_{T} A_{X_{01}} L_{X_{01}}, \beta_{T} \tau A_{X_{11}} Q_{Y_{1}}^{*}\right\} \\
Q_{X_{2}}^{*} & =\min \left\{\beta_{T} A_{X_{02}}^{*} L_{X_{02}}^{*}, \beta_{T} \tau A_{X_{22}}^{*} Q_{Y_{2}}\right\}
\end{aligned}
$$

The equilibrium conditions are shown in Appendix C. Substituting from the relative labour demand conditions (C5), (C6), (C7) and (C8) into the labour market clearing conditions (C9) and solving for labour in each of the four sectors yields:

$$
\begin{aligned}
L_{X_{01}} & =[\hat{B}]^{-1} \bar{L} & L_{Y_{2}} & =\left(1-[\hat{B}]^{-1}\right) \bar{L} \\
L_{X_{02}}^{*} & =[\widehat{D}]^{-1} \overline{L^{*}} & L_{Y_{1}}^{*} & =\left(1-[\widehat{D}]^{-1}\right) \overline{L^{*}}
\end{aligned}
$$

where: 


$$
\begin{aligned}
& {[\hat{B}]=1+\left(\frac{1}{\tau}\right)\left(\frac{1-\alpha}{\alpha}\right)\left(\frac{A_{X_{02}}^{*}}{A_{X_{11}} A_{Y_{1}}^{*}}\right)\left(\frac{A_{X_{11}} A_{Y_{1}}^{*} \tau+A_{X_{01}}}{A_{X_{22}}^{*} A_{Y_{2}} \tau+A_{X_{02}}^{*}}\right)} \\
& {[\widehat{D}]=1+\left(\frac{1}{\tau}\right)\left(\frac{\alpha}{1-\alpha}\right)\left(\frac{A_{X_{01}}}{A_{X_{22}}^{*} A_{Y_{2}}}\right)\left(\frac{A_{X_{22}}^{*} A_{Y_{2}} \tau+A_{X_{02}}^{*}}{A_{X_{11}} A_{Y_{1}}^{*} \tau+A_{X_{01}}}\right)}
\end{aligned}
$$

Notice that, just as in autarky, because we assume that both sectors engage in indirect production, and the coordination cost is assumed to be the same across sectors, the coordination cost does not enter into the labour allocation across sectors, although the trade cost does. The coordination cost however does enter into the production function, resulting in a productivity cost and reducing the amount of each final good available for consumption. As before, consumption of each good depends on each country's national income. Following the same steps as in Section 3.2, given the symmetry of the model, the value of Home's national income is:

$$
p_{X_{1}} Q_{X_{1}}=\frac{\tau A_{X_{11}} A_{Y_{1}}^{*}+A_{X_{01}}}{\tau A_{X_{11}} A_{Y_{1}}^{*}[\hat{B}]} \bar{L}
$$

And Foreign's national income is:

$$
p_{X_{2}}^{*} Q_{X_{2}}^{*}=\frac{\tau A_{X_{22}}^{*} A_{Y_{2}}+A_{X_{02}}^{*}}{\tau A_{X_{22}}^{*} A_{Y_{2}}[\widehat{D}]} \overline{L^{*}}
$$

Home's share of world income is therefore:

$$
\widehat{S_{H}}=\frac{\frac{\tau A_{X_{11}} A_{Y_{1}}^{*}+A_{X_{01}}}{\tau A_{X_{11}} A_{Y_{1}}^{*}[\hat{B}]}}{\left[\frac{\tau A_{X_{11}} A_{Y_{1}}^{*}+A_{X_{01}}}{\tau A_{X_{11}} A_{Y_{1}}^{*}[\bar{B}]} \bar{L}\right]+\left[\frac{\tau A_{X_{22}}^{*} A_{Y_{2}}+A_{X_{02}}^{*}}{\tau A_{X_{22}}^{*} A_{Y_{2}}[\bar{D}]} L^{*}\right]}
$$

Hence equilibrium consumption in the two countries is:

$$
\begin{aligned}
C_{X_{1}} & =\widehat{S_{H}} \beta_{T} A_{X_{01}}[\widehat{B}]^{-1} \bar{L} & C_{X_{1}}^{*} & =\left(1-\widehat{S_{H}}\right) \tau \beta_{T} A_{X_{01}}[\widehat{B}]^{-1} \bar{L} \\
C_{X_{2}} & =\widehat{S_{H}} \tau \beta_{T} A_{X_{02}}^{*}[\widehat{D}]^{-1} \overline{L^{*}} & C_{X_{2}}^{*} & =\left(1-\widehat{S_{H}}\right) \beta_{T} A_{X_{02}}^{*}[\widehat{D}]^{-1} \overline{L^{*}}
\end{aligned}
$$

The threshold values of $\beta_{T}$ are obtained by comparing these consumption levels with consumption under international trade in final goods only (36a) and (36b):

$$
\widehat{\beta_{1 T}}=\frac{\alpha \beta A_{Y_{1}} A_{X_{11}}[\widehat{B}]}{\widehat{S_{H}}\left(A_{Y_{1}} A_{X_{11}}+A_{X_{01}}\right)} \quad \widehat{\beta_{2 T}}=\frac{\alpha \beta A_{Y_{2}}^{*} A_{X_{22}}^{*}[\widehat{D}]}{\widehat{S_{H}}\left(A_{Y_{2}}^{*} A_{X_{22}}^{*}+A_{X_{02}}^{*}\right)}
$$

Values of $\beta_{T}$ greater than the threshold values mean that output with trade in both intermediate and final goods is larger than output with trade in final goods alone. Figure 1 shows that the threshold values depend positively on the domestic coordination $\operatorname{cost} \beta$, while 
for the parameter values chosen, it is negatively related to the trade cost $\tau$; the relationship with $\beta$ is a general result, while the relationship with $\tau$ depends on other parameter values ${ }^{6}$.

Figure 1: Threshold values of $\beta_{1 T}$ as a function of $\beta$ and $\tau$.

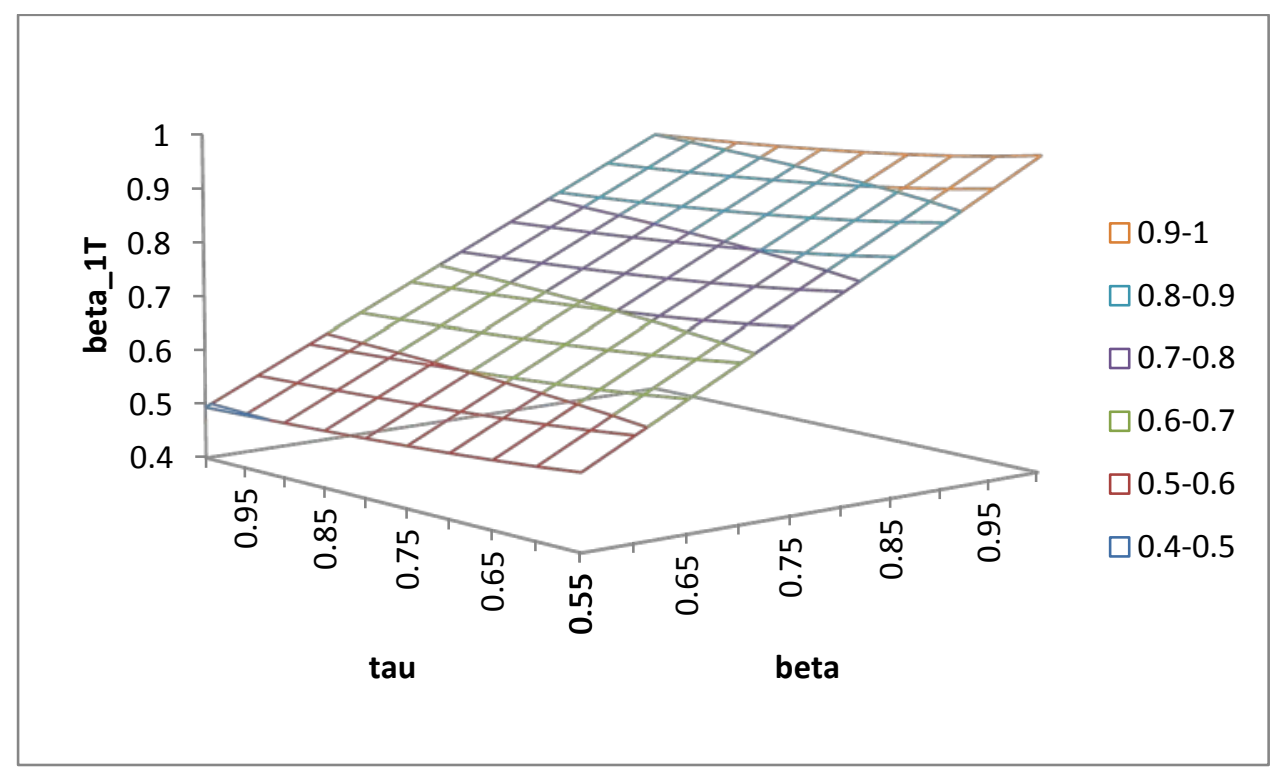

\subsection{A history of the international organisation of production}

The previous subsections have shown how production is organised in the world economy depending on the coordination and trade costs that exist. In this subsection we consider what happens as both trade and coordination costs decrease over time. The outcomes depend in a relatively complex way on these trade and coordination costs; hence we offer here an example of the parameter values under which different configurations exist.

Suppose initially that both types of costs are very high; for example, $\beta=\tau=0.4$ and $\beta_{T}=0.3$. Whilst these may appear to be very large trade costs (equivalent to a trade friction of $150 \%$ ), this is not out of line with the figures quoted in Anderson and van Wincoop (2004), who suggest a total trade barrier of $170 \%$ in developed countries. With such high costs, it is not beneficial to engage in international trade, or indeed to engage in domestic

\footnotetext{
${ }^{6}$ This can also be seen by substituting(42a),(42b) and (45) into (47). Since $\beta$ does not enter into $[\hat{B}],[\widehat{D}]$ or $\left[\widehat{S_{H}}\right]$, there is a direct relationship between $\beta$ and $\widehat{\beta_{1 T}}$ and $\widehat{\beta_{2 T}}$. However, $\tau$ enters into all of $[\widehat{B}]$, $[\widehat{D}]$ and $\left[\widehat{S_{H}}\right]$, and these appear in both the numerator and denominator of $\widehat{\beta_{1 T}}$ and $\widehat{\beta_{2 T}}$, so $\tau$ has a complicated relationship with $\widehat{\beta_{1 T}}$ and $\widehat{\beta_{2 T}}$.
} 
indirect production. This is the situation with Henry Ford's monolithic factory: firms produce final goods directly from raw materials, and there is no international trade.

What happens next depends on whether trade costs decrease faster than coordination costs or vice versa. In the former case, suppose that $\beta=0.4, \beta_{T}=0.3$ as before, and $\tau$ increases to 0.5. This is sufficient to ensure that international trade in final goods with direct production is the most beneficial outcome. In this case Home will specialise in $X_{1}$ and export it to Foreign in exchange for imports of $X_{2}$. On the other hand, if coordination costs decrease faster than trade costs, then autarky with indirect production will occur, for instance if $\beta_{T}=0.3$, and $\tau=0.4$ as before, then $\beta=0.593$ is sufficient to obtain this outcome. Therefore, industries in which trade costs are relatively low compared to coordination costs will be engaged in international trade, whereas industries in which trade costs are relatively high will engage in domestic indirect production.

As both trade and coordination costs continue to fall, production begins to take place indirectly, although only international trade in final goods continues to occur. For example, this occurs if $\beta_{T}=0.3$ as before, and $\beta=\tau=0.625$. Therefore, as trade and coordination costs fall, countries may actually become less specialised as they move from international trade with direct production to international trade with indirect production. And finally, when the cost of coordinating imported intermediate products is sufficiently small relative to the cost of coordinating domestically produced intermediate products $\left(\beta_{T}\right.$ is sufficiently close to $\beta$ ), countries will trade both intermediate and final goods, specialising in the production of intermediates and final goods in which they have a comparative advantage. This is the production structure of the Apple iPod as discussed in the Introduction. Given the parameters assumed above, an example of this occurring is when $\beta=\tau=0.65$, and $\beta_{T}=0.62$.

If inputs are defined as being in the same industry as the final good it is used in, then trade will be intra-industry in nature: Home exports $X_{1}$ and $Y_{2}$ in exchange for imports of $X_{2}$ and $Y_{1}$. Therefore, intra-industry trade can occur only when the cost of transacting internationally is not too large relative to the cost of transacting domestically. In addition, similarly to $\mathrm{Yi}$ (2003), once trade and coordination costs fall to this low level, the volume of trade increases, possibly in a nonlinear way, depending on the parameter values. If international standards such as ISO certification help to reduce these international transactions costs, then this may 
provide a justification for the existence of such standards (see for example Clougherty and Grajek, 2008). A similar role may exist for business networks (see for example Rauch, 2001).

\section{Conclusions}

This paper develops a simple model of international trade with 2 countries, 2 final goods, 2 intermediate goods, and one factor of production. The objective is to explore the structure of production that emerges. Both domestic and foreign outsourcing lead to productivity gains. Despite the simple setup, the model allows for many possible outcomes, depending on the cost of international trade and the cost of coordinating intermediate inputs. When both trade and coordination costs are very high, not only is there no international trade, but firms engage in direct production of final goods (that is, they do not make use of intermediate inputs produced outside the firm). As coordination costs fall, indirect production of final goods occurs with the use of domestic intermediate inputs, while as trade costs fall, international trade in final goods occurs. Finally, when coordination costs for imported intermediates are not too large relative to the coordination costs of domestically produced intermediates, international trade occurs in both intermediate and final goods, and production occurs indirectly through the use of imported intermediates. Hence as trade costs decrease, the international structure of production endogenously becomes more fragmented, and countries become more inter-dependent.

The model in this paper has assumed a single factor of production. Whilst this simplifies the analysis, it also prevents us from analysing the distributional effects of trade in intermediate goods, which has been an important policy issue (see Mankiw and Swagel, 2006). In addition, by assuming only one intermediate good for each final good, the model is unable to address the possibility that decreasing trade and coordination costs may result in an expansion in the range of intermediate inputs being outsourced or offshored. The other key omission is heterogeneity across firms, which would allow for different organisational forms within each sector. Progress along these lines can be made using a model with more than one factor of production, many intermediate goods, and firm heterogeneity of the Melitz (2003) type, and is an important avenue for future research. 


\section{References}

Amiti, Mary and Shang-Jin Wei (2009), "Service offshoring and productivity: Evidence from the US”, The World Economy 32(2): 203-220.

Anderson, James E. and Eric van Wincoop (2004), “Trade costs", Journal of Economic Literature 42(3): 691-751.

Antras, Pol (2003), “Firms, contracts, and trade structure”, Quarterly Journal of Economics 118(4): 1375-1418.

Antras, Pol and Elhanan Helpman (2004), “Global sourcing”, Journal of Political Economy 112(3): 552-580.

Brown, Clair and Greg Linden (2005), "Offshoring in the semiconductor industry: A historical perspective”, Brookings Trade Forum, 279-333.

Clougherty, Joseph A. and Michal Grajek (2008), “The impact of ISO 9000 diffusion on trade and FDI: A new institutional analysis”, Journal of International Business Studies 39(4): 613-633.

Eaton, Jonathan and Samuel Kortum (2002), "Technology, geography, and trade", Econometrica 70(5): 1741-1779.

Ethier, Wilfred J. (1982), "National and international returns to scale in the modern theory of international trade”, American Economic Review 72(3): 389-405.

Feenstra, Robert C. (2009), Offshoring in the global economy, Cambridge, MA, MIT Press.

Feenstra, Robert C and Gordon H. Hanson (1996), "Foreign investment, outsourcing and relative wages”, in Robert C. Feenstra, Gene M. Grossman and Douglas A. Irwin (eds.), The political economy of trade policy: Papers in honor of Jagdish Bhagwati, Cambridge, MA, MIT Press.

Feenstra, Robert C. and Gordon H. Hanson (1997), "Foreign direct investment and relative wages: Evidence from Mexico's maquiladoras”, Journal of International Economics 42(3-4): 371-393.

Fort, Teresa C. (2013), "Breaking up is hard to do: Why firms fragment production across locations”, mimeograph, Tuck School of Business. 
Fujimoto, Takahiro and Yoshinori Shiozawa (2011a), "Inter and intra company competition in the age of global competition: A micro and macro interpretation of Ricardian trade theory”, Evolutionary and Institutional Economics Review 8(1): 1-37.

Fujimoto, Takahiro and Yoshinori Shiozawa (2011b), "Inter and intra company competition in the age of global competition: A micro and macro interpretation of Ricardian trade theory”, Evolutionary and Institutional Economics Review 8(2): 193-231.

Gorg, Holger, Aoife Hanley and Eric Strobl (2008), "Productivity effects of international outsourcing: Evidence from plant-level data”, Canadian Journal of Economics 41(2): 670688.

Gross, Daniel (1997), Forbes greatest business stories, New York, John Wiley \& Sons.

Grossman, Gene M. and Elhanan Helpman (2002), "Integration versus outsourcing in industry equilibrium”, Quarterly Journal of Economics 117(1): 85-120.

Grossman, Gene M. and Esteban Rossi-Hansberg (2008), “Trading tasks: A simple theory of offshoring”, American Economic Review 98(5): 1978-1997.

Grubel, Herbert G. And Peter J. Lloyd (1975), Intra-industry trade: The theory and measurement of international trade in differentiated products, New York, Wiley.

Helpman, Elhanan, Marc J. Melitz and Stephen R. Yeaple (2004), "Export versus FDI with heterogeneous firms”, American Economic Review 94(1): 300-316.

Houseman, Susan (2007), “Outsourcing, offshoring and productivity measurement in United States manufacturing”, International Labour Review 146(1-2): 61-80.

Jones, Ronald W. (2000), Globalization and the theory of input trade, Cambridge, MA, MIT Press.

Jones, Ronald W. and Henryk Kierzkowski (1990), "The role of services in production and international trade: A theoretical framework", in Ronald W. Jones and Anne O. Krueger (eds.), The Political Economy of international trade, Oxford, Basil Blackwell: 31-48.

Knittel, Christopher and Victor Stango (2012), “The productivity benefits of IT outsourcing”, mimeo, MIT.

Linden, Greg, Kenneth L. Kraemer and Jason Dedrick (2007), "Who captures value in a global innovation system? The case of Apple's iPod”, Communications of the ACM 52(3): 140-144. 
Mankiw, N. Gregory and Phillip Swagel (2006), "The politics and economics of offshore outsourcing”, Journal of Monetary Economics 53(5): 1027-1056.

Melitz, Marc J. (2003), “The impact of trade on intra-industry reallocations and aggregate industry productivity”, Econometrica 71(6): 1695-1725.

Olsen, Karsten Bjerring (2006), "Productivity impacts of offshoring and outsourcing: A review”, STI Working Paper 2006/1, OECD.

Rauch, James E. (2001), "Business and social networks in international trade”, Journal of Economic Literature 39(4): 1177-1203.

Ricardo, David (1817), On the principles of political economy and taxation, London, John Murray.

Rodriguez-Clare, Andres (2010), “Offshoring in a Ricardian world”, American Economic Journal: Macroeconomics 2(2): 227-258.

Samuelson, Paul A. (2001), "A Ricardo-Sraffa paradigm comparing gains from trade in inputs and finished goods”, Journal of Economic Literature 39(4): 1204-1214.

Sanyal, Kalyan (1983), “Trade in raw materials in a simple Ricardian model”, Institute for International Economic Studies, Seminar Paper 233.

Sanyal, Kalyan and Ronald W. Jones (1982), “The theory of trade in middle products", American Economic Review 72(1): 16-31.

Shiozawa, Yoshinori (2007), “A new construction of Ricardian trade theory - A manycountry, many-commodity case with intermediate goods and choice of production techniques”, Evolutionary and Institutional Economics Review 3(2): 141-187.

Shiozawa, Yoshinori (2009), "Samuelson's implicit criticism against Sraffa and the Sraffians and two other questions”, Kyoto Economic Review 78(1): 19-37.

Sraffa, Piero (1960), Production of commodities by means of commodities, Cambridge, Cambridge University Press.

Sturgeon, Timothy J. (2002), "Modular production networks: A new American model of industrial organization”, Industrial and Corporate Change 11(3): 451-496.

US Government Accountability Office (2006), “Offshoring: US Semiconductor and software industries increasingly produce in China and India”, US Government Accountability Office Report to Congressional Committees 06-423. 
Yi, Kei-Mu (2003), “Can vertical specialization explain the growth of world trade?”, Journal of Political Economy 111(1): 52-102. 


\section{Appendix A: Equilibrium conditions with international trade in final goods only}

The equilibrium conditions when international trade is allowed in final goods only are as follows:

$$
\begin{aligned}
& p_{X_{1}}=p_{X_{1}}^{*}=\frac{w\left(A_{X_{11}} A_{Y_{1}}+A_{X_{01}}\right)}{A_{X_{01}} A_{X_{11}} A_{Y_{1}}} \quad p_{X_{2}}=p_{X_{2}}^{*}=\frac{w^{*}\left(A_{X_{22}}^{*} A_{Y_{2}}^{*}+A_{X_{02}}^{*}\right)}{A_{X_{02}}^{*} A_{X_{22}}^{*} A_{Y_{2}}^{*}} \\
& \frac{p_{X_{1}}}{p_{X_{2}}}=\left[\frac{A_{X_{02}}^{*} A_{X_{22}}^{*} A_{Y_{2}}^{*}}{A_{X_{01}} A_{X_{11}} A_{Y_{1}}}\right]\left[\frac{A_{X_{11}} A_{Y_{1}}+A_{X_{01}}}{A_{X_{22}}^{*} A_{Y_{2}}^{*}+A_{X_{02}}^{*}}\right]=\frac{\alpha}{1-\alpha}\left(\frac{C_{X_{2}}}{C_{X_{1}}}\right) \\
& \frac{C_{X_{2}}}{C_{X_{1}}}=\frac{A_{X_{02}}^{*} L_{X_{02}}^{*}}{A_{X_{01}} L_{X_{01}}}=\frac{A_{X_{22}}^{*} A_{Y_{Y}}^{*} L_{Y_{2}}^{*}}{A_{X_{11}} A_{Y_{1}} L_{Y_{1}}} \\
& \frac{L_{X_{02}}^{*}}{L_{X_{01}}}=\left(\frac{1-\alpha}{\alpha}\right)\left(\frac{A_{X_{22}}^{*} A_{Y_{2}}^{*}}{A_{X_{11}} A_{Y_{1}}}\right)\left(\frac{A_{X_{11}} A_{Y_{1}}+A_{X_{01}}}{A_{X_{22}}^{*} A_{Y_{2}}^{*}+A_{X_{02}}^{*}}\right) \\
& \frac{L_{Y_{2}}^{*}}{L_{Y_{1}}}=\left(\frac{1-\alpha}{\alpha}\right)\left(\frac{A_{X_{02}}^{*}}{A_{X_{01}}}\right)\left(\frac{A_{X_{11}} A_{Y_{1}}+A_{X_{01}}}{A_{X_{22}}^{*} A_{Y_{2}}^{*}+A_{X_{02}}^{*}}\right) \\
& A_{X_{01}} L_{X_{01}}=A_{X_{11}} A_{Y_{1}} L_{Y_{1}} \quad \leftrightarrow \quad L_{X_{01}}=\frac{A_{X_{11}} A_{Y_{1}}}{A_{X_{01}}} L_{Y_{1}} \\
& A_{X_{02}}^{*} L_{X_{02}}^{*}=A_{X_{22}}^{*} A_{Y_{2}}^{*} L_{Y_{2}}^{*} \quad \leftrightarrow \quad L_{X_{02}}^{*}=\frac{A_{X_{22}}^{*} A_{Y_{2}}^{*}}{A_{X_{02}}^{*}} L_{Y_{2}}^{*} \\
& L_{X_{01}}+L_{Y_{1}}=\bar{L} \quad L_{X_{02}}^{*}+L_{Y_{2}}^{*}=\overline{L^{*}} \quad w=w^{*}
\end{aligned}
$$

\section{Appendix B: Equilibrium conditions with international trade in both intermediate and final goods}

The equilibrium conditions when international trade is allowed in both intermediate and final goods are as follows:

$$
\begin{aligned}
& p_{X_{1}}=p_{X_{1}}^{*}=\frac{w A_{X_{11}} A_{Y_{1}}^{*}+w^{*} A_{X_{01}}}{A_{X_{01}} A_{X_{11}} A_{Y_{1}}^{*}} \\
& p_{X_{2}}=p_{X_{2}}^{*}=\frac{w^{*} A_{X_{22}}^{*} A_{Y_{2}}+w A_{X_{02}}^{*}}{A_{X_{02}}^{*} A_{X_{22}}^{*} A_{Y_{2}}} \\
& \frac{p_{X_{1}}}{p_{X_{2}}}=\left[\frac{A_{X_{02}}^{*} A_{Y_{2}} A_{X_{22}}^{*}}{A_{X_{01}} A_{Y_{1}}^{*} A_{X_{11}}}\right]\left[\frac{A_{X_{11}} A_{Y_{1}}^{*}+A_{X_{01}}}{A_{X_{22}}^{*} A_{Y_{2}}+A_{X_{02}}^{*}}\right]=\frac{\alpha}{1-\alpha}\left(\frac{C_{X_{2}}}{C_{X_{1}}}\right) \\
& \frac{C_{X_{2}}}{C_{X_{1}}}=\frac{A_{X_{02}}^{*} L_{X_{02}}^{*}}{A_{X_{01}} L_{X_{01}}}=\frac{A_{X_{22}}^{*} A_{Y_{2}} L_{Y_{2}}}{A_{X_{11}} A_{Y_{1}}^{*} L_{Y_{1}}^{*}} \\
& \frac{L_{X_{02}}^{*}}{L_{X_{01}}}=\left(\frac{1-\alpha}{\alpha}\right)\left(\frac{A_{Y_{1}} A_{X_{22}}^{*}}{A_{Y_{1}}^{*} A_{X_{11}}}\right)\left(\frac{A_{X_{11}} A_{Y_{1}}^{*}+A_{X_{01}}}{A_{X_{22}}^{*} A_{Y_{2}}+A_{X_{02}}^{*}}\right)
\end{aligned}
$$




$$
\begin{array}{lcc}
\frac{L_{Y_{2}}}{L_{Y_{1}}^{*}}=\left(\frac{1-\alpha}{\alpha}\right)\left(\frac{A_{X_{02}}^{*}}{A_{X_{01}}}\right)\left(\frac{A_{X_{11}} A_{Y_{1}}^{*}+A_{X_{01}}}{A_{X_{22}}^{*} A_{Y_{2}}+A_{X_{02}}^{*}}\right) & \\
A_{X_{01}} L_{X_{01}}=A_{X_{11}} A_{Y_{1}}^{*} L_{Y_{1}}^{*} & \leftrightarrow & L_{X_{01}}=\frac{A_{X_{11}} A_{Y_{1}}^{*}}{A_{X_{01}}} L_{Y_{1}}^{*} \\
A_{X_{02}}^{*} L_{X_{02}}^{*}=A_{X_{22}}^{*} A_{Y_{2}} L_{Y_{2}} & \leftrightarrow & L_{X_{02}}^{*}=\frac{A_{X_{22}}^{*} A_{Y_{2}}}{A_{X_{02}}^{*}} L_{Y_{2}} \\
L_{X_{01}}+L_{Y_{2}}=\bar{L} & L_{X_{02}}^{*}+L_{Y_{1}}^{*}=\overline{L^{*}} & w=w^{*}
\end{array}
$$

\section{Appendix C: Equilibrium conditions with trade and coordination costs}

The equilibrium conditions when trade in both intermediate and final goods is allowed in the presence of trade and coordination costs are (setting $w=w^{*}$ ):

$$
\begin{aligned}
& p_{X_{1}}=\tau p_{X_{1}}^{*}=\frac{w\left(A_{X_{11}} A_{Y_{1}}^{*} \tau+A_{X_{01}}\right)}{\beta_{T} \tau A_{X_{01}} A_{X_{11}} A_{Y_{1}}^{*}} \\
& p_{X_{2}}=\frac{p_{X_{2}}^{*}}{\tau}=\frac{w\left(A_{X_{22}}^{*} A_{Y_{2}} \tau+A_{X_{02}}^{*}\right)}{\beta_{T} \tau^{2} A_{X_{02}}^{*} A_{X_{22}}^{*} A_{Y_{2}}} \\
& \frac{p_{X_{1}}}{p_{X_{2}}}=\tau\left[\frac{A_{X_{02}}^{*} A_{Y_{2}} A_{X_{22}}^{*}}{A_{X_{01}} A_{Y_{1}}^{*} A_{X_{11}}}\right]\left[\frac{A_{X_{11}} A_{Y_{1}}^{*} \tau+A_{X_{01}}}{A_{X_{22}}^{*} A_{Y_{2}} \tau+A_{X_{02}}^{*}}\right]=\frac{\alpha}{1-\alpha}\left(\frac{C_{X_{2}}}{C_{X_{1}}}\right) \\
& \frac{C_{X_{2}}}{C_{X_{1}}}=\frac{\tau A_{X_{02}}^{*} L_{X_{02}}^{*}}{A_{X_{01}} L_{X_{01}}}=\frac{\tau A_{X_{22}}^{*} A_{Y_{2}} L_{Y_{2}}}{A_{X_{11}} A_{Y_{1}}^{*} L_{Y_{1}}^{*}} \\
& \frac{L_{X_{02}}^{*}}{L_{X_{01}}}=\left(\frac{1-\alpha}{\alpha}\right)\left(\frac{A_{Y_{2}} A_{X_{22}}^{*}}{A_{Y_{1}}^{*} A_{X_{11}}}\right)\left(\frac{A_{X_{11}} A_{Y_{1}}^{*} \tau+A_{X_{01}}}{A_{X_{22}}^{*} A_{Y_{2}} \tau+A_{X_{02}}^{*}}\right) \\
& \frac{L_{Y_{2}}}{L_{Y_{1}}^{*}}=\left(\frac{1-\alpha}{\alpha}\right)\left(\frac{A_{X_{02}}^{*}}{A_{X_{01}}}\right)\left(\frac{A_{X_{11}} A_{Y_{1}}^{*} \tau+A_{X_{01}}}{A_{X_{22}}^{*} A_{Y_{2}} \tau+A_{X_{02}}^{*}}\right) \\
& \beta_{T} A_{X_{01}} L_{X_{01}}=\beta_{T} \tau A_{X_{11}} A_{Y_{1}}^{*} L_{Y_{1}}^{*} \quad \leftrightarrow \quad L_{X_{01}}=\frac{\tau A_{X_{11}} A_{Y_{1}}^{*}}{A_{X_{01}}} L_{Y_{1}}^{*} \\
& \beta_{T} A_{X_{02}}^{*} L_{X_{02}}^{*}=\beta_{T} \tau A_{X_{22}}^{*} A_{Y_{2}} L_{Y_{2}} \quad \leftrightarrow \quad L_{X_{02}}^{*}=\frac{\tau A_{X_{22}}^{*} A_{Y_{2}}}{A_{X_{02}}^{*}} L_{Y_{2}} \\
& L_{X_{01}}+L_{Y_{2}}=\bar{L} \quad L_{X_{02}}^{*}+L_{Y_{1}}^{*}=\overline{L^{*}}
\end{aligned}
$$

\section{Appendix D: Comparison with Samuelson's (2001) results}

The equivalent parameter values used in Samuelson’s (2001) paper are:

$$
\begin{array}{llll}
A_{X_{1}}=2 & A_{X_{2}}=0.5 & A_{Y_{1}}=0.5 & A_{Y_{2}}=2 \\
A_{X_{01}}=8 & A_{X_{11}}=4 & A_{X_{02}}=2 & A_{X_{22}}=1 \\
A_{X_{1}}^{*}=0.5 & A_{X_{2}}^{*}=2 & A_{Y_{1}}^{*}=2 & A_{Y_{2}}^{*}=0.5
\end{array}
$$




$$
\begin{aligned}
& A_{X_{01}}^{*}=2 \quad A_{X_{11}}^{*}=1 \quad A_{X_{02}}^{*}=8 \quad A_{X_{22}}^{*}=4 \\
& \alpha=0.5 \quad \bar{L}=\bar{L}^{*}=1
\end{aligned}
$$

Given these parameter values, the autarkic utility level is 0.5 under direct production, and is 0.411 under indirect production. Hence as Samuelson (2001) suggests, under autarky it does not make sense to engage in indirect production.

Trade in final goods alone yields utility of 1 - a two-fold increase over the autarkic utility level, as Samuelson (2001) finds. Finally, trade in both intermediate and final goods yields utility equal to 2 - a two-fold increase over trade in final goods alone, or a four-fold increase over the autarkic utility level. This is different from what Samuelson obtains; he gets utility equal to 3 when there is trade in both intermediate and final goods. The reason for this difference is that Samuelson's model, by defining intermediate goods as the same as final goods, sidesteps the fact that intermediate goods need to be produced before final goods, hence enables him to obtain a larger gain from trade in intermediate inputs. In our formulation, by decoupling intermediate goods from final goods, we are able to take into account this timing issue, and find that the gains from trade in intermediate inputs, whilst large, is not as large as that obtained by Samuelson (2001).

In addition, Samuelson (2001) claims that “... all consumptions will become unboundably large” (Samuelson, 2001, p. 1207) when labour productivity in converting intermediate inputs into final goods $A_{X_{01}}$ and $A_{X_{02}}^{*}$ become very large. This does not happen in our formulation, again because we have decoupled intermediates from final goods. Instead, given the values above, utility approaches 4 as $A_{X_{01}}$ and $A_{X_{02}}^{*}$ become very large. The reason is that when these parameters become very large, almost all labour is used in producing the intermediate inputs. Unless labour productivity in these intermediate inputs becomes very large as well, simply altering labour productivity in assembling the final product will not yield unbounded levels of consumption and utility. 